\title{
Relato de experiência de um atendimento a Deficiente Intelectual com o uso taxonomia de Bloom no Atendimento Educacional Especializado
}

\author{
Experience report of an Intellectual Disabled service with the use of Bloom taxonomy in Specialized
} Educational Service

Informe de experiencia de um servicio de Discapacidad Intelectual com el uso de Bloom taxonomy em el Servicio Educativo Especializado

\section{Resumo}

Neste artigo apresenta-se um relato de experiência acerca da educação inclusiva, com recorte para o atendimento educacional especializado realizado na Sala de Recursos Multifuncionais (SRM), apontando como o planejamento baseado na taxonomia de Bloom pode contribuir para o aprendizado significativo do estudante, em específico, o públicoalvo da educação especial atendidos na SRM dentro das escolas regulares. Neste sentido, pretende-se dialogar acerca das estratégias de ensino e buscar a luz das teorias meios para que se efetive um aprendizado autônomo, baseado nos objetivos educacionais propostos para cada nível de ensino. Tal análise foi realizada com um aluno com deficiência intelectual moderada, dificuldades de articulação da fala e que não apresenta domínios de organização mental esperados para a idade. $\mathrm{O}$ aluno possui acompanhamento multiprofissional na área da saúde, o qual é realizado em parceria com os profissionais da escola. Vale destacar que, este trabalho colaborativo entre os profissionais da saúde e da educação trouxe inúmeros benefícios ao desenvolvimento do estudante.

Palavras-chave: Educação inclusiva; Atendimento educacional especializado; Taxionomia de Bloom.

\begin{abstract}
This article presents an experience report about inclusive education, with a clipping for the specialized educational care performed in the Multifunctional Resources Room (MRR), pointing out how planning based on Bloom taxonomy can contribute to the significant learning of the student, in particular, the target audience of special education attended in the MRR within the regular schools. In this sense, it is intended to dialogue about teaching strategies and seek the light of theories means for an autonomous learning to be effective, based on the educational objectives proposed for each level of education. This analysis was performed with a student with moderate intellectual disability, speech articulation difficulties and who does not present mental organization domains expected for age. The student has multiprofessional follow-up in the health area, which is carried out in partnership with the school professionals. It is worth mentioning that this collaborative work among health and education professionals has brought numerous benefits to student development.
\end{abstract}

Keywords: Inclusive education; Specialized educational service; Bloom taxionomy.

\section{Resumen}

Este artículo presenta un informe de experiencia sobre la educación inclusiva, centrándose en el servicio educativo especializado que se lleva a cabo en el Aula de Recursos Multifuncionales (SRM), señalando cómo la planificación basada en la taxonomía de Bloom puede contribuir al aprendizaje significativo de los estudiantes, específicamente, el 
público objetivo de la educación especial atendida en el SRM dentro de las escuelas regulares. En este sentido, se pretende dialogar sobre las estrategias de enseñanza y buscar la luz de las teorías significativas para lograr un aprendizaje autónomo, a partir de los objetivos educativos propuestos para cada nivel educativo. Este análisis se realizó con un alumno con discapacidad intelectual moderada, con dificultades de articulación del habla y que no presenta dominios de organización mental esperados para su edad. El alumno tiene un seguimiento multidisciplinar en el área de la salud, que se realiza en colaboración con los profesionales de la escuela. Cabe destacar que este trabajo de colaboración entre los profesionales de la salud y la educación aportó numerosos beneficios al desarrollo del alumno.

Palabras clave: Educación inclusiva; Asistencia educativa especializada; Taxionomía de Bloom.

\section{Introdução}

Este artigo apresenta-se a partir de um estudo de caso, relatando a experiência no atendimento educacional especializado na Sala de Recursos Multifuncionais (SRM), com um aluno de 12 anos, que frequenta o nono ano do Ensino Fundamental II na escola regular. A partir desta análise, oportunizou-se estabelecer a Taxonomia de Bloom com os objetivos de aprendizagem para desenvolver as habilidades educacionais do estudante.

A taxonomia é utilizada em diferentes áreas e no contexto educacional, pois oferece base para o desenvolvimento de instrumentos e avaliações, bem como para elaboração de estratégias para promoção do conhecimento, estimulando o desempenho dos alunos em diferentes níveis: cognitivo, afetivo e psicomotor, também denominados de táxons, esses grupos são organizados para alcançar todos os níveis de conhecimento (Rodrigues Junior 2016).

A taxonomia parte do princípio de estimulação dos conceitos mais simples para os mais complexos gerando certo grau de dificuldade condizente com o nível do estudante, para que ele consiga superar os obstáculos e alcançar o conhecimento. Tal estratégia facilita a intermediação do professor e reforça a necessidade da participação do estudante de forma autônoma e responsável no processo de ensino e aprendizagem (Trevisan \& Amaral, 2016).

Parte-se do princípio de que todo desenvolvimento cognitivo necessita ser estimulado e repensado, de modo a assegurar desde os conceitos básicos até os mais aplicados, sempre respeitando as habilidades iniciais do estudante para planejar as habilidades que ele ainda irá alcançar. Na educação inclusiva esse fator é preponderante, pois, para buscar atingir o aluno em determinado conteúdo, buscamos formas e ferramentas para todo processo.

Sabe-se que o aprendiz passa por graus de desenvolvimento no seu processo de aprendizagem, portanto, tais características necessitam ser respeitadas e consideradas durante todo planejamento educacional, por isso é de suma importância que os profissionais da educação pensem estratégias que favoreçam o desenvolvimento dos alunos, considerando as suas diferenças.

Portanto, neste artigo abordar-se-á um relato de experiência, realizado com o sujeito em tela que possui deficiência intelectual, utilizando a taxonomia de Bloom, partindo das suas características, competências e atitudes esperadas nas categorias do desenvolvimento, enfatizando a importância da utilização da taxonomia no Atendimento Educacional Especializado - AEE a partir de um planejamento que busque atingir o cognitivo do aluno.

\section{Metodologia}

Este estudo respalda-se na compreensão de metodologia como um caminho que liga o pensamento e prática dentro da realidade (Minayo, 1994). Essa concepção acerca da metodologia como um caminho, nos faz compreender que este estudo configura-se como um relato de experiência de abordagem qualitativa (GIL, 2018). Ttrata-se da utilização da taxonomia de Bloom com um sujeito com deficiência intelectual que faz parte do público do Atendimento Educacional Especializado (AEE).

Para apropriação acerca da temática foi realizada inicialmente a pesquisa bibliográfica, para apropriação teórica acerca do tema, uma vez que a taxonomia de Bloom seria utilizada no ambiente escolar. Após a compreensão teórica acerca da 
taxonomia de Bloom foram planejados os Atendimentos Especializados que seriam utilizados com o sujeito da pesquisa, posteriormente aplicada a taxonomia de Bloom e por fim descrita em forma de estudo de caso.

\section{Objetivos de Aprendizagem e o Atendimento Educacional Especializado}

Neste segundo contexto busca-se elencar alguns procedimentos e atitudes que podem ser ampliadas nas escolas a fim de, em conjunto, encontrar as melhores técnicas e metodologias para beneficiar não somente os alunos com deficiência, mas todos os que fazem parte do contexto escolar inclusivo. Segundo Ortiz e Dorneles (2018) a transformação que está ocorrendo no meio educacional, acarreta mudanças para o professor e para o aluno, promovendo a autonomia desses sujeitos mediante as informações que eles têm acesso.

Conforme Nóvoa (1995) não basta apenas os professores terem cursos e formações, isto é, não é apenas a formação que assegura a educação de qualidade, mas sim, a reflexão acerca da prática docente e as mudanças atitudinais. Desta forma, a escola, portanto, deverá promover momentos de discussão e formação para que os professores do Ensino Regular possam fixar uma ponte pedagógica com os profissionais que atuam na Sala de Recursos Multifuncionais (SRM), para que o professor especialista em Educação Especial também possa designar um tempo para atender os professores demonstrando alguns métodos que podem auxiliar a prática docente em sala de aula.

O professor especialista tem a possibilidade de explicar aos demais professores as diferentes possibilidades de atuação junto ao aluno com deficiência e, inclusive exemplificar como a teoria da taxonomia de Bloom pode favorecer para averiguar o nível de conhecimento do aluno para que o professor da sala regular consiga elaborar seus planejamentos de modo condizente com o estágio de aprendizagem do seu aluno com deficiência, partindo de objetivos claros e precisos.

A proposta política inclusiva parte da oportunidade de aprendizagem baseada na diversidade dos alunos. Rodrigues (2006) afirma que ao assumir que a diferença é uma característica inerente aos sujeitos, faz-se necessário pensar a sala de aula e todo o ambiente escolar como um espaço heterogêneo, o qual necessita de estratégias de ensino e aprendizagem que atenda a diversidade.

Partindo dessa perspectiva, na escola não se efetiva somente a transmissão do conhecimento e da informação por parte do professor e o aprendizado por parte do aluno, mas designa-se como um espaço de interação, onde os agentes deverão mediar o conhecimento e promover a relações para efetivação do processo de ensino e a aprendizagem. Assim, fica claro que, a simples inserção dos alunos com deficiência, sem nenhum tipo de apoio ou assistência aos sistemas regulares de ensino, pode redundar em fracasso, na medida em que sem as devidas orientações os professores passam a utilizar metodologias que se distanciam da necessidade dos alunos, o que pode afetar o processo de aprendizagem dos alunos (BUENO, 1999).

Vale destacar que, a formação docente não se constrói por acumulação (de cursos, de conhecimentos ou de técnicas), mas sim, através de um trabalho de reflexividade crítica sobre as práticas e de (re)construção permanente de uma identidade pessoal. Assim, a Taxonomia poderá fortalecer o planejamento do professor e promover maior envolvimento do aluno. Pois, o princípio dos usos dos verbos para os objetivos considera o estado de conhecimento do estudante, partindo da premissa que para ele continuar ele deve recordar, reconhecer, analisar o conteúdo para que o mesmo possa ser aprofundado.

\section{Educação Inclusiva na Perspectiva da Taxonomia de Bloom}

Historicamente a pessoa com deficiência foi vista como alguém que não deveria ser exposto na sociedade, ou seja, deveria viver isolada, sem contato com os demais sujeitos sociais. Sabe-se que, em muitas civilizações eles eram tratados até como não humanos (Matarazzo, 2009). 
Estes sujeitos viviam a margem da sociedade, sem exceções, recebiam dois tipos de tratamento no período da História Antiga e Medieval, a rejeição e sua eliminação sumária, ou abandonada para os cuidados de caráter assistencialista. A história nos conta que na Roma Antiga as famílias tinham o direito de matar seus filhos quando eles recebiam o diagnóstico de deficiência, em especial as físicas que eram identificadas logo ao nascerem, sendo sumariamente sacrificados, evitando assim um contato com a sociedade e com a família (França, 2014).

$\mathrm{O}$ ato de matar ou abandonar as pessoas com deficiência, não tinha relação com a classe social, era um misticismo que acompanhava todas as famílias. Muitos outros povos também agiam de forma excludente, a exemplo de Esparta, que ao identificar nos bebês alguma anomalia eles eram sacrificados, assim como qualquer pessoa que adquirisse alguma deficiência ao longo de sua vida, podendo ser lançados ao mar ou de um precipício.

Entretanto, baseando-se em Aristóteles que defendia o cidadão, surge a compreensão de que não se deve tratar igualmente aquele que não é igual, de forma que a sociedades atenienses defendia maneiras diferenciadas para o tratamento de pessoas com deficiência, sendo amparados e protegidos pela sociedade (França, 2014).

Nesta perspectiva, tendo como base os registros históricos, é possível compreender que o período denominado de Cristianismo significou uma nova forma de ver o outro, promovendo os direitos e deveres de todos na sociedade. É importante destacar que, a doutrina Cristã estava atrelada ao campo da caridade, humildade, amor, respeito. Foram com base nesses princípios, que foram criadas unidades hospitalares para o atendimento e cuidado de alguns casos deficiência, enxergando não a pessoa, mas a sua deficiência, vislumbrando a cura desses sujeitos (Matarazzo, 2009).

A doutrina Cristã toma para si o cuidado e a remissão dessas pessoas, por acreditar que a deficiência estava relacionada a castigos divinos, então objetivando a conversão das famílias dessas pessoas com deficiência, o arrependimento de seus pecados e consequentemente a cura da deficiência, a igreja passa a acolher esses sujeitos, oferecendo um suporte não só físico, mas principalmente espiritual.

Todavia, a Igreja Católica que inicialmente pregava preceitos de fé e amor ao próximo, agora mantinha uma postura de diferenciação, adotando comportamentos discriminatórios e de perseguição, substituindo a caridade pela rejeição aos que não se encaixam nos padrões de normalidade impostos pela sociedade, contribuindo significativamente para a marginalização social das pessoas com deficiência, uma vez que a igreja ocupava grande papel de doutrinação na sociedade (França, 2014).

Nos séculos XV a XVII a sociedade passou por um processo de mudanças, ficando esse período conhecido como o "Renascimento", a época ficou marcada como a era de mudança do pensamento, mas foi no "Iluminismo" que surgiu os princípios, direitos e deveres da humanidade, sendo esse período fundamental para compreendermos o advento dos direitos que se universalizaram, partindo de uma filosofia humanista que passa a enxergar todos com os mesmos direitos e deveres, partindo de uma perspectiva inclusiva (Bianchetti, 1995).

Após o período inicial de mudanças, surgiram alguns debates com a preocupação de que as pessoas com deficiência deveriam ter uma atenção própria, diferente, a qual estaria voltada para suas necessidades. De forma que, a partir do século XVI, foram dados passos decisivos no avanço de ações, ideias e atendimento às pessoas com deficiência, com atenção especial as pessoas com deficiência auditiva, pois eles não conseguiam se comunicar na forma oral, eram consideradas “ineducáveis", ou pelo caráter religioso, ou possuído por espíritos malignos, por isso precisavam de uma atenção mais minuciosa no que tange o seu processo formativo (Bianchetti, 1995).

Assim, as pessoas com deficiência passaram a fazer parte do ambiente e escolar e ganharam força para conviver em sociedade, dentro de uma perspectiva inclusiva, a qual está reconhecida legalmente, através da Constituição Federal de 1988, que estabelece como um dos objetivos principais da República Federativa do Brasil "promover o bem de todos, sem preconceitos de origem, raça, idade e quaisquer outras formas de discriminação" (Art. $3^{\circ}$, Inciso IV), apresentando que a educação é um direito de todos, tendo em vista o pleno desenvolvimento da pessoa, o exercício da cidadania e a qualificação para o trabalho (Art. 205). 
Foi com base em leis nacionais que as pessoas com deficiência passaram a fazer parte do espaço escolar, entretanto, a atual conjuntura educacional, bem como, as ações que garantem políticas públicas, cada vez mais acessíveis a toda a sociedade, não dão conta de todas as especificidades, nem dentro e nem fora da escola, visto que as pessoas que tem no Atendimento Educacional Especializado (AEE) representa um percentual mínimo diante da ocupação das inúmeras deficiências em todos os espaços sociais.

De acordo com as Diretrizes Operacionais para o Atendimento Educacional Especializado na Educação Básica, modalidade Educação Especial (2009)

O atendimento educacional especializado - AEE tem como função identificar, elaborar e organizar recursos pedagógicos e de acessibilidade que eliminem as barreiras para a plena participação dos alunos, considerando suas necessidades específicas. Esse atendimento complementa e/ou suplementa a formação dos alunos com vistas à autonomia e independência na escola e fora dela (Brasil, 2009).

Tendo como base as Diretrizes Operacionais da Educação Especial para o Atendimento Educacional Especializado na Educação Básica (2008) o AEE tem a função de auxiliar o aluno com deficiência em seu processo de ensino e aprendizagem para que o mesmo adquira autonomia. É importante ainda destacar que, frente a necessidade e dos alunos com deficiência, esse sujeito enxerga-se por vezes exposto, sem possibilidade para realização de atividades básicas. Diante desta análise, podemos questionar, até que ponto o estudante com deficiência está incluído de fato em sala de aula? (Aradillas, 2020)

Neste questionamento, a Taxonomia de Bloom com os objetivos educacionais que consideram os aspectos cognitivos: que dá sentido a informação, deixando o contexto apreendido mais produtivo, a aplicação do conhecimento; emocional (afetivo) para recepção, resposta, avaliação, organização e caracterização e assim internaliza e assimila, dentro do conceito da pessoalidade; e o psicomotor da aprendizagem, com a percepção do seu redor, ter predisposição para atividades, ter resposta guiada e se apropriar do conhecimento, e por fim com resposta mecânica, conseguindo estar no meio e tornar hábito as ações, Figura 1, comumente visto em formato de pirâmide, que se apresenta quão maior é o objetivo e o verbo na pirâmide, maior é aprendizado, a base da pirâmide se inicia com memorizar, (Marcheti \& Belhot, 2010)

Figura 1 - Verbos Taxonomia de Bloom.

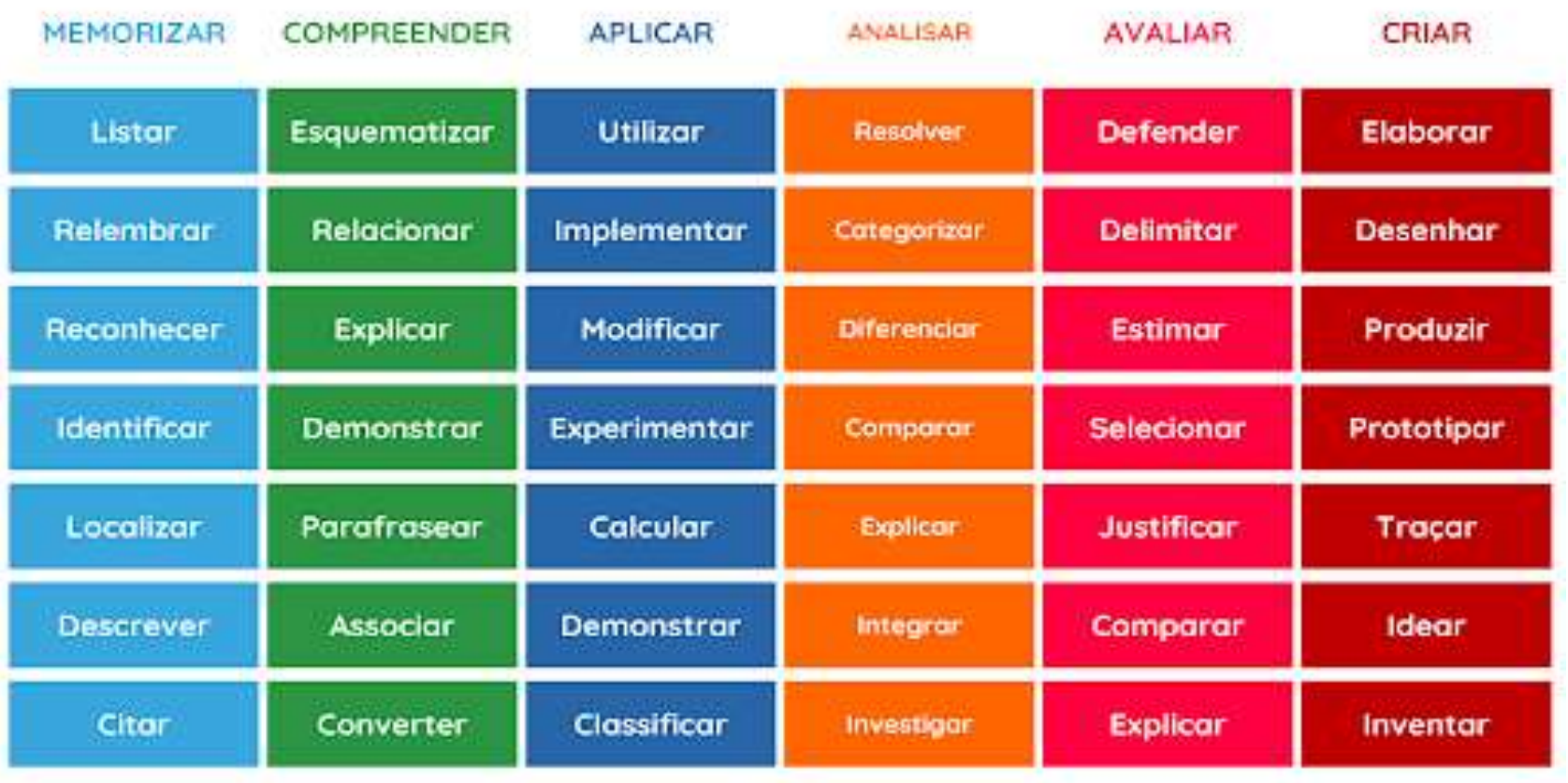

Fonte: http://of6.info/taxonomia-de-bloom/ 
Diante desse arcabouço que versa sobre os táxons que auxiliam os professores na prática de ensinar, podemos incluir nessa proposta de aprendizagem o estudante público-alvo da educação especial em sala de aula, entendemos que esses objetivos são essenciais para construção da aprendizagem, principalmente no atendimento da pessoa com deficiência intelectual, visto os resultados nesse relato de experiência, apresentando a aplicação na prática dos táxons para concretizar a aprendizagem.

\section{Relato de Experiência: Taxonomia para o Planejamento no Atendimento a Deficiente Intelectual.}

A experiência na Educação Especial teve início em 2015, com atuação na Sala de Recursos Multifuncionais (SRM) em uma escola do campo. Esta experiência impulsionou a atividade colaborativa e dinâmica dentro da escola. $\mathrm{O}$ aluno deste estudo é um adolescente do sexo masculino, com 12 anos, que possui deficiência intelectual e é acompanhado por uma equipe multidisciplinar. Trata-se de um aluno comunicativo, que apresenta parceria entre escola e família e que busca sempre participar das aulas, sendo dinâmico e bem-humorado.

Neste sentido, observando suas dificuldades e suas características de aprendizagem, partiu-se para o planejamento a partir da taxonomia de Bloom, buscando estabelecer os conteúdos básicos e necessários para o primeiro trimestre de aula, sendo (re)planejado ao término de cada semestre, a fim de evidenciar os avanços e consequentemente expor ao aluno situações mais complexas e necessárias para o seu aprendizado, seguindo as intenções estabelecidas para estudante, no ambiente do Atendimento Educacional Especializado (AEE), visando sempre a autonomia junto ao ensino regular, com a estrutura de três perguntas a serem respondidas: "O quê?", "Como?" e "Para quê?".

Deve ser considerada neste ponto, a avaliação, que em muitos momentos é utilizada para mensurar e atribuir o conceito de nota e não para verificar as pendências e retomar a aprendizagem dos conteúdos não assimilados. O trabalho colaborativo é primordial nesse processo, pois permite interação entre o professor especialista e o professor do ensino regular, assegurando que os objetivos sejam condizentes e o grau de maturidade do aluno seja respeitado dentro da sua deficiência.

Neste sentido, o Plano de Atendimento Individual (PAI) pode nortear não somente o trabalho na Sala de Recursos Multifuncionais (SRM), mas, todo o corpo docente que trabalhou com o estudante, pois o Atendimento Educacional Especializado (AEE) se tornou um aporte de interação, participação e referência ao ensino regular.

De acordo com a taxonomia as aprendizagens são apresentadas de forma hierárquica, baseada em fatos e que dentro da sala de recursos foi efetivada a partir de projetos educativos, cada projeto tendo em vista o cotidiano do estudante e também a realidade da escola e sua comunidade.

O projeto contemplou um trimestre e envolveu leitura, produções escritas, narrações, dramatizações, produções artísticas e oralidade, incentivando o estudante nas suas produções, partindo do conteúdo mais básico ao mais avançado de forma progressiva. O projeto denominou-se "Eu e minha Escola" onde semanalmente foi oferecida uma aula diversificada, visando os interesses do estudante e possibilitando aproximar o conteúdo de sua prática.

Partindo do princípio de solução de problemas, o aluno foi provocado, incentivado e indagado, despertando a curiosidade e a investigação na busca pelo conhecimento, na organização das atividades as habilidades de atenção, concentração, coordenação motora fina, lateralidade e espacialidade foram atribuídas no planejamento, visto que o aluno apresenta limitações nessas áreas e que, portanto, sempre devem ser evidenciadas durante os encontros.

Esse breve relato, visa apresentar os pontos positivos do emprego da taxonomia para o aprendizado, estabelecendo os objetivos do planejamento e partindo do conhecimento do aluno para superar suas dificuldades. Pretende-se utilizar dessa experiência para a Educação Especial Inclusiva no formato das Salas de Recursos Multifuncionais (SRM) e poder favorecer o público-alvo da Educação Especial sempre de forma colaborativa e flexível, socializando o estudante ao grupo e estabelecendo autonomia dentro do espaço regular de ensino, favorecendo o que de fato entendemos por Educação Inclusiva. 


\section{Considerações Finais}

Não devemos considerar um término em se tratando de um relato de experiência acerca do processo de ensino e aprendizagem de uma pessoa com deficiência, incluído na escola regular, pois nesse processo cotidianamente surgem novos desafios, com os quais a escola ainda está aprendendo a lidar e buscando atender a necessidades dos alunos como um todo, respeitando a individualidade do processo de cada um deles.

Vale destacar que, não existe uma fórmula correta para atuação ou um único método eficiente, uma vez que, cabe a equipe escolar conhecer os seus alunos, pesquisar e refletir acerca das necessidades do seu público para que assim consiga decidir quais os melhores caminhos e possibilidades para que o aluno obtenha êxito em seu processo de ensino e aprendizagem.

Por isso, este relato apresenta considerações acerca dos efeitos positivos da utilização da taxonomia de Bloom, neste caso em específico, com o qual foi possível identificar que a taxonomia de Bloom pode ser tornar um importante instrumento de planejamento para o professor desenvolver o trabalho colaborativo e inclusivo, a partir de graus de desenvolvimento a serem atingidos pelo estudante.

Desta forma, considera-se importante que outras pesquisas sejam realizadas acerca da utilização da taxonomia de Bloom, principalmente com relatos de experiência relacionando a utilização da mesma com pessoas com deficiência, para que outros professores possam fundamentar a sua prática para promoção de um processo de ensino e aprendizagem no Atendimento Educacional Especializado, realizado na Sala de Recursos Multifuncionais de qualidade.

\section{Referências}

Aradillas, A. L. S. (2020). Teorías del aprendizaje en el contexto educativo. Digital del Tecnológico de Monterrey.

Bianchetti, L. (1995). Aspectos Históricos da Educação Especial. Revista Brasileira de Educação Especial. 03.

Brasil. (1996). Lei n 9 9.394, de 20 de dezembro de 1996. Estabelece as Diretrizes e Bases da Educação Nacional. Diário Oficial da União. Brasília.

Brasil. (2004). Constituição Federativa da República Brasileira de 1988. Senado Federal.

Brasil. (2009). Conselho Nacional de Educação. Câmara de Educação Básica. Resolução CNE/ CEB n. 4, de 2 de outubro de 2009. Institui Diretrizes Operacionais para o Atendimento Educacional Especializado na Educação Básica, modalidade Educação Especial. Diário Oficial da União.

Bueno, J.G.(1999).Criançascomnecessidadeseducativasespeciais, política educacionaleaformaçãodeprofes sores:generalistasou especialistas.Revista Brasileira de Educação Especial. 3(5), 7-25.

França, S. D. (2014). Inclusão de alunos com NEE no ensino superior: um estudo de caso na Universidade Estadual de Montes Claros (UNIMONTES). 2014. Tese (Doutorado em Ciências da Educação) - Programa de Doutoramento em Ciências da Educação, Universidade Trás-os-Montes e Alto Douro, Vila Real, Portugal. https://www.rbhcs.com/rbhcs/article/view/205/199.

Gil, A. C. (2018). Como elaborar projetos de pesquisa. (8a ed.), Atlas.

Marcheti, A. P. do C. F. \& BELHOT, R. V. (2010). Taxonomia de Bloom: revisão teórica e apresentação das adequações do instrumento para definição de objetivos instrucionais. 2010. https://www.scielo.br/scielo.php?script=sci_arttext\&pid=S0104-530X2010000200015

Matarazzo, C. (2009). Vai encarar? A nação (quase) invisível de pessoas com deficiência. Editora Melhoramentos.

Minayo, M. C. S. (1994). Ciência, técnica e arte: o desafio da pesquisa social. In: Minayo, M. C. S. (Org.). Pesquisa social: teoria, métodos e criatividade. Vozes.

Nóvoa, A. (1995). Formação de professores e profissão docente. In: Nóvoa, A. (Coord.). Os professores e a sua formação. Dom Quixote, 1995.

ORTIZ, J. O. de S. \& DORNELES, A. M. (2018). Uso da taxonomia de Bloom digital gamificada em atividades coletivas no ensino de química: reflexões teóricas e possibilidades. Ludus Scientiae. 2(2), 14-25. https://revistas.unila.edu.br/relus/article/view/1475/1519

Rodrigues, D. (org). (2006). Inclusão e Educação: doze olhares sobre Educação Inclusiva. Summus Editorial.

Rodrigues Junior, J. F. (2016). A Taxonomia de Objetivos Educacionais. Ed. UNB. (2a ed.).

Trevisan, A. L. \& Amaral, R. G. (2016) A Taxionomia revisada de Bloom aplicada à avaliação: um estudo de provas escritas de Matemática. Ciênc. Educ., 22(2), 451-464. https://www.scielo.br/pdf/ciedu/v22n2/1516-7313-ciedu-22-02-0451.pdf 